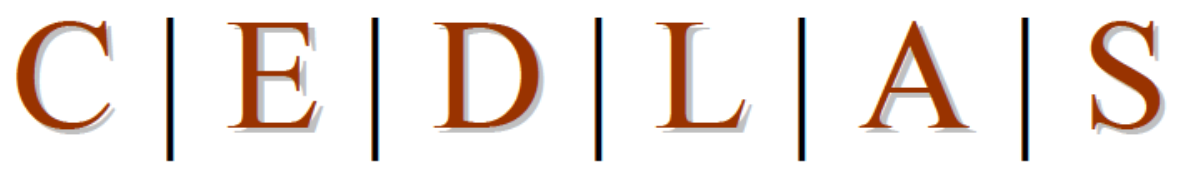

Centro de Estudios

Distributivos, Laborales y Sociales

Maestría en Economía

Facultad de Ciencias Económicas

Universidad Nacional de La Plata

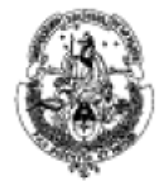

\title{
Pro-Poor Trade Policy in Sub-Saharan Africa
}

\author{
Alessandro Nicita, Marcelo Olarreaga y Guido Porto
}

Documento de Trabajo Nro. 134

Julio, 2012

ISSN 1853-0168 


\title{
Pro-Poor Trade Policy in Sub-Saharan Africa*
}

\author{
Alessandro Nicita ${ }^{\dagger}$ \\ UNCTAD
}

\author{
Marcelo Olarreaga ${ }^{\ddagger}$ \\ University of Geneva \\ and CEPR
}

September 2011

\author{
Guido Porto ${ }^{\S}$ \\ Universidad Nacional \\ de La Plata
}

\begin{abstract}
The objective of this paper is to estimate the potential pro-poor bias in the existing structure of protection in six Sub-Saharan African (SSA) countries (i.e., whether it redistributes income from rich to poor households). We also explore the extent to which the barriers faced by SSA exporters in the rest-of-the-world are biased in favor of poor or rich household. To this end, we start with a simple agricultural household production model and propose an extension to include adjustments in labor income associated with changes in unskilled and skilled wages. We then build indicators that capture the differences in welfare changes across income levels associated with the elimination of SSA's own trade protection, as well as trade protection on SSA's export bundle by the rest-of-the-world. Results suggest that SSA's own trade policy is biased in favor of poor households. In contrast, the trade policies of SSA's trading partners tend to be biased in favor of SSA's rich households, especially when ad-valorem equivalents of NTMs are taken into account.
\end{abstract}

JEL CODES: F13, F16

Key Words: Trade policy, wage elasticities, poverty, Sub-Saharan Africa.

\footnotetext{
*We thank Matias Horenstein, Sean Lawrence, and Mario Piacentini for their outstanding research assistance. We are also grateful to Olu Ajakaiye, Richard Baldwin, Anne-Célia Disdier, Peter Egger, Joe Francois, Bernard Hoekman, Michele Ruta, Akiko Suwa-Eisenmann, and Cristina Terra, as well as participants at EAAE meetings in Zurich, the PEGGED conference at Villars, and seminars at THEMA-Cergy, and the University of Geneva for their helpful comments and suggestions. Funding from a BNPP (Bank of Netherland Partnership Program) grant at the World Bank is greatly appreciated. All errors are our responsibility.

${ }^{\dagger}$ UNCTAD, email : alessandro.nicita@unctad.org

$\ddagger$ University of Geneva and CEPR, email: marcelo.olarreaga@unige.ch

$\S$ Universidad Nacional de La Plata, Calle 6 e/47 y 48, 1900 La Plata, Argentina. email: guido.porto@depeco.econo.unlp.edu.ar
} 


\section{Introduction}

Trade liberalization makes some individuals better off and others worse off and this income redistribution can be systematically biased in favor of or against poor individuals. Reductions in tariffs and non-tariff barriers, both at home and abroad, affect consumer and producer prices, which in turn affect household production, household consumption, labor earnings, and transfers. Since the poor and the rich generally consume different bundles and have different sources of income, trade policy changes will affect them differently, which may lead to a systematic bias in trade policy. In this paper, we propose an empirical framework to measure the pro-poor bias in trade protection and we apply this framework to six countries in Sub-Saharan Africa (SSA): Burkina Faso, Cameroon, Côte d'Ivoire, Ethiopia, Gambia, and Madagascar. The analysis covers the bias of SSA's own trade policies as well as the bias associated with market access conditions in the rest-of-the-world. To assess these biases, our framework relies on very disaggregated trade and trade policy data, which we match with household level information on sources of income and consumption patterns.

Trade policy is pro-poor if the existing structure of protection benefits poor households proportionately more than rich households. Note, that this implies that the elimination of the existing structure of protection is actually pro-rich in the sense that the resulting percentage change in welfare is larger for rich than for poor households. We thus propose a simple indicator of pro-poor bias given by the difference between the percentage change in welfare of the average household in the top and bottom deciles of the income distribution. A larger index reveals a larger poverty bias in the existing structure of trade protection (i.e., a larger redistribution from rich to poor households associated with the existing levels of protection).

To identify pro-poor trade policies, we need to compute the changes in welfare at the household level that would be caused by the elimination of the observed levels of trade protection. We work with a framework where changes in household welfare are approximated by changes in household real income and where these changes in welfare can be decomposed into consumption, production and labor income effects (Deaton, 1997; Winters et al., 2004). Measuring the consumption and production effects is straightforward with information on 
consumption and production shares. Labor income effects, which are potentially very important because labor earnings represent between 30 and 70 percent of total household income in our target SSA countries, are harder to measure. In particular, we need to calculate the share of labor income derived from different types of labor (skilled and unskilled) and to estimate the responses of the returns of those different types of labor to changes in prices, i.e., the wage-price elasticities.

The literature has estimated these elasticities by exploiting the time-series variation in prices and in household surveys. See for instance Nicita (2009) for Mexico, Porto (2006, 2010) for Argentina, and Ural Marchand (2011) for India. This identification strategy requires time-series data that is typically unavailable for most Sub-Saharan African countries. To circumvent this problem, we put forward a framework to estimate wage-price elasticities based on duality theory. Young's theorem suggests that the second cross derivatives of the revenue function (which characterizes the GDP of the country) with respect to good prices and factor endowments are equal, which implies that the first derivative of factor prices with respect to good prices (the wage-price elasticities) is equal to the first derivative of quantities with respect to factor endowments. This is convenient because of the availability of detailed information on quantities exported and imported at the tariff line level, as well as data on factor endowments. We can then estimate the impact of changes in the endowment of unskilled and skilled labor on imported and exported quantities at the six-digit level of the Harmonized System (HS), which are then equal to the wage-price elasticities at the same level of disaggregation.

A fundamental advantage of our methodology is that it allows for the estimation of the responses of wages to price changes of very dissagregated goods. This is impossible in a framework using household data because of limited degrees of freedom. However, this is important because trade policy is determined at the tariff line level, and there is significant variation across tariff lines within industries in terms of both protection levels and production techniques (i.e., factor intensities). For example, the HS 52 category ("cotton") includes products such as "raw cotton, not carded or combed" (HS 520100) and "woven cotton fabrics with less than 85 percent cotton" (HS 521011). Both production techniques and 
trade protection in these two goods can be very different. For instance, in Burkina Faso, Cameroon, Côte d'Ivoire, Gambia, and Madagascar, the tariff on raw cotton is half that of the tariff on woven cotton fabrics. In Ethiopia, the tariff on woven cotton fabrics is three times larger than the tariff on raw cotton (30 versus 10 percent). In the United States (an export market for SSA), tariffs on raw cotton are a fifth of the tariffs on woven cotton fabrics, and the latter is subject to non-tariff barriers (technical regulations). The covariance between trade protection and production techniques is likely to matter for the impact of changes on trade policy on skilled and unskilled wages. Aggregation at higher levels than the tariff line level at which trade policy is determined may lead to aggregation bias that is avoided using the methodology developed in this paper.

Goldberg and Pavcnik (2004), in their review of the empirical literature on trade, income inequality and poverty, also called for a higher product disaggregation in empirical studies of the impact of trade on wages. The high product aggregation in household surveys makes the identification of worker reallocation across very aggregated sectors difficult and thus may reduce the estimates of the impact of trade reforms on wages. Allowing for these general equilibrium effects may significantly affect the estimates of the previous literature on trade and wages which were often undertaken within a partial equilibrium framework at a much more aggregated level. For an early example of a partial equilibrium approach see Revenga (1997), and for an early call to introduce general equilibrium effects when analyzing the impact of trade reforms on wages see Harrison and Hanson (1999). ${ }^{1}$

Our empirical results suggest that the elimination of SSA's own trade policies leads to increases in unskilled wages, and decreases in skilled wages. Since SSA is mostly abundant in unskilled labor, and thus protection is often granted on imported, skilled-intensive goods, these results are consistent with the standard Stolper-Samuleson predictions. Nevertheless, with the exception of Ethiopia, domestic trade policy is biased in favor of poor households. ${ }^{2}$ This is mainly explained by the production (agricultural sales) channel which, with the

\footnotetext{
${ }^{1}$ Note that our approach cannot capture the heterogeneity in wage-price elasticities across worker characteristics as in Porto $(2006,2010)$ or Nicita (2009). While they can estimate different impacts for workers in different regions and with different experience, here we can only capture the heterogeneity across characteristics for which we have endowment data available across countries and time.

${ }^{2}$ This implies that the removal of trade barriers will bring relatively larger benefits to rich households.
} 
exception of Ethiopia, tends to be pro-poor. Indeed, given that agricultural sales tend to represent a larger share of poor households' income, the decline in prices associated with the removal of agricultural protection tends to hurt poor households relatively more than rich households.

Interestingly, the consumption (or expenditure) channel is neither systematically pro-rich, nor pro-poor. It varies across countries depending on the correlation between the structure of protection and consumption patterns among poor and rich households. In four of our six target countries, the consumption effect is pro-rich suggesting that the removal of protection will tend to benefit more rich than poor households. Note also that the contribution of the consumption effect to the pro-poor bias in protection is always smaller (in absolute value) than the contribution of the production effect.

Contrary to SSA's own protectionism, the protection of the rest-of-the-world on SSA's export bundle tends to be biased in favor of rich households. Indeed, the removal of protection by the rest-of-the-world will bring larger gains to poor households than to rich households. This is mainly driven by a pro-rich bias in the production (agricultural sales) channel. The labor income channel is mildly pro-poor in most countries, which again is consistent with Stolper-Samuelson type effects. ${ }^{3}$

The remainder of the paper is organized as follows. Section 2 describes the analytical framework used to measure the pro-poor bias of trade policy. Section 3 describes our three-step empirical methodology for the implementation of the analytical setup. In the first step, we describe the harmonization of different household surveys to compute budget and income shares at the household level in each SSA country. In the second step, we measure the restrictiveness of trade policy in SSA, as well as the restrictiveness of SSA's trading partners on exports from SSA. In the last step, we describe our empirical methodology to estimate the impact that changes in trade policy in SSA and abroad have on wages of skilled and unskilled workers in SSA. Section 4 presents the results and section 5 concludes.

\footnotetext{
${ }^{3}$ One could explore the impact on social welfare of these redistributional consequences of trade reform using a framework similar to the one recently put forward by Francois and Rojas-Romagosa (forthcoming) where a pro-poor bias in the existing structure of trade protection would imply gains from society from the removal of trade protection that would be smaller than those obtained for an economy with representative individual.
} 


\section{Pro-Poor Trade Policy}

Our measure of the pro-poor bias of trade policy is based on estimates of the differential impact of trade barriers on the real income of the poor vis-à-vis the non-poor, or more generally, on the differential impact of trade on household incomes at different levels of living. The theoretical framework that we use to derive the welfare impacts of price changes is based on the standard model introduced by Deaton $(1989,1997)$ and expanded by Ravallion (1990), Coello et al. (2011), Porto (2006, 2010) and Nicita (2009). Household $h$ welfare is measured with the indirect utility function $V_{h}$ :

(1) $V_{h}=V_{h}\left(y_{h}, \mathbf{p}\right)$

where $y_{h}$ is household income and $\mathbf{p}$ is a vector of good prices. In our analysis, and because of limitations of our data, we focus on the prices of traded goods (non-traded goods, except for labor, are not considered here).

Household income is determined in a farm-household model, as in Sign, Squire and Strauss (1986) or Benjamin (1992). Each household has an endowment of labor, which needs to be allocated to various possible activities, and of other factors of production, such as land or assets (assumed for simplicity to be fixed). Households can consume some leisure, work on their own farm to produce goods to sell to the market, or sell labor off-farm (or purchase labor in the labor market). Households may also enjoy transfers. Household income is defined as:

$$
y_{h}=w L_{h}+\sum_{g} \pi_{h, g}(\mathbf{p})+G_{h}+\phi_{h} T
$$

where $w$ is the wage rate, $L_{h}$ is the (net) amount of labor sold in the market by household $h$, $\pi_{h, g}$ are profits obtained from selling good $g$ in the market; $G_{h}$ are government transfers to household $h$ not associated with tariff revenue, $\phi_{h}$ is the share of tariff revenue redistributed to household $h$ and $T=\sum_{g} t_{g} p_{g}^{*} m_{g}$ (where $p_{g}^{*}$ is the international price of the good $g, m_{g}$ is good $g$ imports and $t_{g}$ is good $g$ tariff rate) is the tariff revenue collected over all goods $g$ subject to tariffs. 
To derive the first order welfare impact of a change in price $p_{i}$, we need to totally differentiate (1) and (2). As in most of the literature, we assume that markets are perfect and complete, so that the principle of separability holds. For our purpose, this implies that households optimize production and consumption decisions based on market prices and that these market prices are also the relevant shadow prices faced by households. ${ }^{4}$ Using Roy's identity and Hotelling Lemma, we get

$$
d V_{h}=\frac{\partial V_{h}}{\partial \ln y_{h}}\left(-s_{h}^{g} d \ln p_{g}+\theta_{h}^{w} \varepsilon_{w p_{g}} d \ln p_{g}+\theta_{h}^{g} d \ln p_{g}+\theta_{h}^{T} d \ln T\right)
$$

where $s_{h}^{g}$ is the share of good $g$ in the consumption bundle of household $h, \varepsilon_{w p_{g}}$ is the elasticity of wages with respect to changes in $p_{g}, \theta_{h}^{w}$ is the share of household income derived from labor earnings, $\theta_{h}^{g}$ is the share of income from sales of the production of good $g$, and $\theta_{h}^{T}$ is the share of tariff revenue accrued by the household. Note that $\partial V_{h} / \partial \ln y_{h}$ is the private marginal utility of income, which is unobservable. In practice, we ignore this term. Conceptually, from a policy evaluation standpoint, we care about the social utility of income for different households (e.g., the poor vis-à-vis the rich) and not about the private marginal utility of income (which is instead relevant for individuals). ${ }^{5}$ This means that, in the empirical analysis, we focus on the changes in household real income, $d \widetilde{y}_{h}^{g}$ :

$$
d \widetilde{y}_{h}^{g}=-s_{h}^{g} d \ln p_{g}+\theta_{h}^{w} \varepsilon_{w p_{g}} d \ln p_{g}+\theta_{h}^{g} d \ln p_{g}+\theta_{h}^{T} d \ln T .
$$

Our objective in this paper is to measure the different pieces of equation (4) and to use these estimates to assess the pro-poor bias of trade policy. Before doing this, we begin with a brief conceptual interpretation of the first order approximation in (4).

Our starting point is the change in prices $d \ln p_{g}$ brought about by trade policy. It is clear that there is a relationship between tariffs and product prices. How this relationship works, however, is more complicated. One issue is the extent of price transmission from trade policy to domestic prices. Due to lack of data to estimate these pass-through elasticities, here we

\footnotetext{
${ }^{4}$ Benjamin (1992) provides evidence in favor of the separability principle in Indonesia but Jacoby (1993), for Peru, and Le (2009), for Vietnam, report instead potential failures of this assumption.

${ }^{5}$ See Deaton (1997).
} 
will assume perfect price transmission (i.e., unitary elasticities). ${ }^{6}$ Since there is evidence that trade policy does not pass-through to prices one to one (Nicita, 2009; Goldberg and Knetter, 1997), we in practice would be overestimating the welfare impact of trade. However, since in this paper we care about the pro-poor bias (or, more generally, the differential impact at different income levels) of trade policy, the distributional conflict will be correctly identified. ${ }^{7}$

The other issue is the price effect of different trade policy. We study both protection at home, and protection abroad. Protection at home is simply the structure of tariff levied by each particular country on its imports. Protection abroad refers to market access barriers (that is, the rest-of-the-world's trade policies) vis-à-vis SSA. Both types of trade protection affect border prices (and thus consumer and producer prices given our unitary pass-through elasticity assumption) and we compare below the difference in their pro-poor bias. In section 3.2, we explain how we utilize trade and protection data to generate estimates of protection at home and protection abroad and how we use these estimates to calculate price changes.

The first term on the right hand side of (4) measures the impact of a price change on expenditures. When prices go up consumers are worse off because their real income declines (keeping nominal income constant); conversely, consumers are better off when prices decline. To first order, this effect can be well-approximated with the shares of the budget spent on good $g\left(s_{g}\right)$. To implement this, we need information on those budget shares which can be retrieved, for example, from household survey data.

The second term is the first order impact of the price change on profits. This term shows that income increases when the price of a good produced by the household goes up and decreases when prices decline. To first order, this can be approximated by the share of income derived from the own-production of this good in total income $\left(\theta_{h}^{g}\right)$. This information can also be retrieved from the household surveys.

In fact, the major objective of the household survey collection and data work described

\footnotetext{
${ }^{6}$ Note that this does not imply that world prices, producer prices and consumer prices are equal, but simply that there are proportional to each other.

${ }^{7}$ Unless, of course, the pass-through elasticities are household specific. While they might as well be, if price transmission depends on regional or individual characteristics, it is extremely difficult to identify that heterogeneity in our data. A possibility would be to estimate the index within type of regions (rural, urban), or within type of individuals if price transmission were to systematically vary along one of these dimensions.
} 
in Section 3 is to extract the budget shares, income shares and labor income shares in different economic activities. While there are no major difficulties in computing these pieces of information from the available data, some aggregation procedures will be needed to make the trade data compatible with the household survey data. We discuss these issues in section 3.1.

The third term on the right-hand side of the welfare impact (4) is the impact of prices on wage income. The estimation of this term requires, first, estimates of the share of income derived from labor earnings, which can also be recovered from household surveys. Second, we need to estimate the wage-price elasticities linking changes in prices with changes in wages. Conceptually, product prices affect factor prices via adjustments in factor markets. A higher price of good $g$ causes firms in sector $g$ to expand, and perhaps firms in other sectors to contract. Stronger demand for labor in expanding sectors increases the demand for labor and pushes wages up, but weaker demand for labor in contracting sectors pushes wages down. The final response of wages will depend on the relative size of these impacts. In section 3.3, we discuss how we estimate these wage-price elasticities in our sample of African countries, using a methodology that does not require the use of several household surveys across time.

Finally, the last term in (4) measures changes in household income due to changes in government transfers brought about by changes in tariff revenue. The way tariff revenue is distributed back to the household is complex. Instead of monetary transfers, public revenues supposedly affect households via the consumption of public goods such as education, health or infrastructure. Measuring these impacts has proved to be extremely difficult in practice. Alternatively, assuming that households benefit from public transfers that are proportional to their level of pre-shock income, implies that all households will experience the same percentage change in total income due to changes in government transfers following changes in tariff revenue. ${ }^{8}$ This implies that we could abstract from changes in government transfers if we adopt a measure of pro-poor bias that is neutral to percentage changes in revenue that are common to all individuals. This will guide our choice of measure of pro-poor bias below,

\footnotetext{
${ }^{8}$ Indeed, under this assumption $\theta_{h}^{T} d \ln T=T /\left(\sum_{h} y_{h}\right) d \ln T=d T /\left(\sum_{h} y_{h}\right)$, which does not depend on $h)$.
} 
so that we do not have to worry about the last term in (4).

But before turning into a measure of the pro-poor bias in the structure of protection, we need to have a measure of the welfare change for each household associated with the entire structure of protection, rather than with the change in the price of a single good. This is simply done by summing the changes in welfare in (4) over all goods $g$. Assuming as argued before that government transfers are proportional to the pre-shock level of income, omitting changes in transfers, our measure of changes in total household real income is

$$
d \widetilde{y}_{h}=\sum_{g}-s_{h, g} d \ln p_{g}+\sum_{g} \theta_{h}^{w} \varepsilon_{w p_{g}} d \ln p_{g}+\sum_{g} \theta_{h}^{i} d \ln p_{g}+\sum_{g} \alpha_{g}
$$

where $\alpha_{g}$ is the percentage change in government revenue (and therefore transfers) associated with changes in the price of good $g$ (again note that $\alpha_{g}$ does not depend on $h$ and therefore is common to all households).

Finally, we measure the pro-poor bias by the welfare differences between rich and poor households associated with the elimination of both tariff and non-tariff barriers. To operationalize this idea, we define first a vector of average welfare effects (i.e., real income changes) at varying level of well-being, $\overline{\Delta W}_{l p c e}$ :

(6) $\overline{\Delta W}_{l p c e}=E\left[d \widetilde{y}_{h} \mid \ln p c e\right]$,

where pce is the per capita expenditure of the household - our definition of well-being. We then compare the relative magnitudes of $\overline{\Delta W}_{l p c e}$ for households at different points of the spectrum of the $(\log )$ per capita expenditure distribution. We define the index as the difference in the percentage change in real income (welfare) of the average household in top $d_{r}$ income deciles and the percentage change in real income of the average household in the bottom $d_{p}$ income deciles:

$$
P_{d}=E\left[d \widetilde{y}_{h} \mid Q_{h}=d_{r}\right]-E\left[d \widetilde{y}_{h} \mid Q_{h}=d_{p}\right]
$$

where $Q_{h}$ is the quintile to which household $h$ belongs to (in terms of its per capita 
expenditure). In the empirical application, we set $d_{r}$ and $d_{p}$ at the top and bottom 40 percent of the income distribution, and then check for robustness using the top and bottom 20 and 10 percent of the income distribution. Several points are worth making. First, $P_{d}$ does not depend on the value of $\sum_{i} \alpha_{g}$. Second, a positive value of $P_{d}$ implies that following the elimination of trade barriers, the percentage change in income for rich households is larger than for poor households. Thus the trade reform is biased against the poor, as they will earn relatively less than the rich. This implies that the status-quo (i.e., the existing trade policy) will tend to be pro-poor when $P_{d}$ is positive.

In order to check that our measure of pro-poor bias is not missing large changes in intra-poor or intra-rich income, we estimate equation (6) with standard non-parametric regression models of the welfare impacts given by (5) on the log of per capita expenditure, $\ln$ pce. $^{9}$ Then, we inspect plots of these non-parametric regressions. If the regression function slopes up with $d \ln p c e$, we say that the trade policy is pro-poor, as the elimination of the existing structure of protection will lead to larger welfare changes for rich households. Conversely, the existing trade policy is pro-rich if it slopes down.

\section{Implementing the Formulas}

The empirical implementation of the formulas needed to estimate the pro-poor bias of trade policy, at home and abroad, requires several steps and different sources of data. Most of our analysis is based on household survey data, which provide the microdata on budget shares and income shares (including labor income shares) that allow us to estimate household-specific welfare impacts. Then, we need to match these data with the trade data that we use to measure protection at home and abroad. This requires first harmonizing the product disaggregation in the household surveys to a common level, so that our measure of pro-poor bias is comparable across countries, and then filtering this product disaggregation into the trade and trade policy classification system (the Harmonized System). Finally, to estimate the changes in real income at the household level given in (5) we also need to

\footnotetext{
${ }^{9}$ Here we ignore the last term in (5) which will only shift uniformly the non-parametric regression.
} 
estimate wage elasticities with respect to changes in prices. In this section, we undertake each of these steps in turn, by describing the various types of data used in our analysis and the concordances we made to match these various datasets. Finally, we discuss the methodology we developed to estimate wage-price elasticities for skilled and unskilled workers at the tariff line level.

\subsection{The Household Surveys: Budget Shares and Income Shares}

We work with household surveys for six Sub-Saharan countries, namely Burkina Faso, Cameroon, Côte d'Ivoire, Ethiopia, Gambia, and Madagascar. These countries were chosen based on data availability and some degree of comparability in the survey's coverage. The name of the surveys and some basic characteristics are listed in Table 1. Sample sizes range from over 25 thousand households in Ethiopia to below 2 thousands in Gambia. The share of the population residing in rural areas is often high. The highest share is in Burkina Faso with 69 percent of the population living in rural areas. The lowest is in Cameroon with 35 percent of the population in rural areas.

Table 2 presents demographic summary statistics from the surveys, including total population, its average age structure, and average years of education of the working population, at the national level and both in rural and urban areas. As expected, there is a lot of variation in the total population of the sample countries: 55.5 million live in Ethiopia, and only 1.8 in Gambia. There are no striking differences in terms of average age across countries and regions. The African population appears to be young, with average age of roughly 21-27 years in all countries (Banerjee and Duflo, 2007). African households tend to be large, especially in rural areas. The average household size is typically higher than 5 members. Finally, formal education (measured by years of education) is low everywhere. Countries with the highest average number of years of education are Côte d'Ivoire and Gambia, with close to 9 years of education, whereas Burkina Faso and Ethiopia show less than two years of average education. The level of education is strikingly lower in rural areas.

While all the surveys we work with collect information on incomes and expenditures, they decompose expenditures and incomes into different sub-categories. This creates a problem 
when trying to build comparable aggregates across surveys. To tackle this issue, we aggregate both the expenditure and the income in the surveys into a common classification of goods across countries. To this end, we built "templates" to map the information at the highest level of disaggregation to the different homogeneous categories (across surveys) that we will use in the analysis. We used two different templates, one for the standardization of consumption (and own-consumption) categories, and another one for income standardization.

The expenditure template is in Table 3. There are four levels of disaggregation. The fourth level, the most detailed one, includes very disaggregated categories, such as corn, wine and cigarettes. At the third level, these products are aggregated into more comprehensive categories such as cereals, alcohol and tobacco. Similarly, level 2 includes categories such as staple-food, non-staple-food and energy, and level 1 includes the most aggregated categories, such as agriculture, manufacture and services. Finally, a similar template is used for income standardization, going from very disaggregated categories such as sales of corn, beans, rice, etc. (level 4), to sales of cereals (level 3), to sales of staple food or non-staple food (level 2), to sales of agricultural goods (level 1). This template is in Table 4.

The household surveys are useful for us because we need the data on budget and income shares to calculate the household-specific welfare impacts of trade policy. Tables 5 and 6 report the shares of income earned in different economic activities (at level 1) and various expenditure shares (also at level 1) for the top and bottom 40 percent of the income distribution. We only report the shares of income and expenditure that are related to trade policy. For example, autoconsumption, services expenditures or incomes, etc., are not included in these totals. The sum of the columns gives an idea of the share of income and expenditure that is likely to be affected by trade policy. Not surprisingly, a large share of the income of African households at the bottom of the income distribution comes from sales of agriculture goods and from unskilled labor income, and very little from skilled labor. ${ }^{10}$ At the top of the income distribution, while sales and unskilled labor income are still the dominant source of income, skilled labor takes a significantly larger share. In Cameroon, for instance, the share of skilled labor in total income of the rich reaches almost 20 percent.

\footnotetext{
${ }^{10} \mathrm{~A}$ worker is defined as skilled if he has more than 9 years of education.
} 
Household expenditures are, for the most part, allocated to food consumption both at the bottom and the top of the income distribution (see Table 6). Expenditure on other goods which prices can be changed by trade policy reforms never represents more than 21 percent of total expenditure by either bottom or top income quintile households. The largest share is found among rich households in Ethiopia.

\subsection{Trade and Protection Data: Trade Policy and Price Changes}

Turning to trade and protection data, the import and export data are from United Nation's Comtrade. Trade flows are available at the six-digit level of the Harmonized System (HS-6) for the year 2006. Trade policy data, including information on tariffs and non-tariff barriers is drawn from Kee, Nicita and Olarreaga (2009). This information is also available at the HS-6 digit level. The data on ad-valorem equivalents of NTBs are available for most of the large developed markets such as the US, the EU, Japan, and Canada (although only for the year 2001). Except for Côte d'Ivoire and Burkina Faso, data on NTBs for our target countries is not very comprehensive.

For the purpose of building the indicator of pro-poor bias in trade policy, we need to convert the trade and trade policy information into the classification of goods and activities that we created to harmonize the household surveys. To do this, we constructed a concordance that converts HS 6-digit lines into our standardized household survey classification. The concordances are cumbersome but straightforward. ${ }^{11}$ Filtering the trade data (imports and exports) is simple as we just need to add up the different components within a given category (similar to what we did with the household survey data). However, the trade policy aggregation is much more complex because of two major aggregation hurdles that arise when measuring trade restrictiveness: aggregation of different forms of trade policies, and aggregation across goods with different economic importance.

The first aggregation problem arises because trade policy can take many different forms: tariffs, quotas, non-automatic licensing, antidumping duties, technical regulations, monopolistic measures, subsidies, and so on. This first aggregation problem is solved using

\footnotetext{
${ }^{11}$ And they are available from the authors upon request.
} 
the ad-valorem equivalents of non-tariff barriers estimates of Kee, Nicita and Olarreaga (2009) that are obtained by first estimating the impact of non-tariff barriers on quantities imported and then transforming the quantity impact into a price-equivalent using import demand elasticities.

The second aggregation problem arises when one wants to aggregate trade protection which is set at a very detailed level into some composite good (the product categories described in Tables 3 and 4). Commonly used aggregation procedures, such as simple averages, import-weighted averages and frequency or coverage ratios, do not have a sound theoretical basis. For example, imports subject to high protection rates are likely to be small, and therefore, will be attributed small weights in an import-weighted aggregation. This would underestimate the restrictiveness of those tariffs. Also, the lack of a sound theoretical basis may lead to strange results. For example, the contribution to the import-weighted average of goods subject to prohibitively high tariffs is the same as the contribution of goods subject to zero tariffs. Indeed, none of these goods affect the import weighted-average (for a given level of aggregate imports). Also, when computing simple average tariffs, very low tariffs on economically meaningless goods would downward bias this measure of trade restrictiveness.

To tackle these problems, we follow Anderson and Neary (2005) and the empirical extension in Kee, Nicita and Olarreaga (2009) to create measures of trade restrictiveness, which include both tariffs and non-tariff barriers at different levels of our homogeneous classification of goods. More specifically, to measure the effect of a given country's trade policies on its domestic prices, we use the tariff trade restrictiveness index (TTRI) and the overall trade restrictiveness index (OTRI). The difference between the TTRI and OTRI is that the OTRI includes the effect of both tariff and non-tariff measures (NTM), while the TTRI measures only the effect of tariffs. Both the TTRI and the OTRI represent the uniform tariff equivalent that would keep aggregate imports constant within a composite of the new classification of goods in the standardized household surveys. They are calculated as a weighted average of the levels of protection at the 6-digit of the harmonized system using import values and import demand elasticities as weights. By taking into account the 
elasticity of import demand with respect to prices, we give relatively more weight within the new composite to six-digit goods with a more sensitive import demand (those goods for which smaller movements in prices produce larger shifts in imports). TTRI and OTRI are calculated at different levels of the new homogenous classification of goods described in Tables 3-4.

Formally, we define the tariff trade restrictiveness index (TTRI) as:

$$
\text { (8) } T T R I_{i, g}=\sum_{x, n \varepsilon g} t_{i, x, n} \frac{m_{i, x, n} \eta_{i, n}}{\sum_{x, n \varepsilon g} m_{i, x, n} \eta_{i, n}} \text {, }
$$

where $i$ denotes the importing country for which we are calculating the TTRI, $g$ is the composite good which includes a subset of goods $n$ at the HS-6 digit level, and $x$ identifies the exporting partner country from which country $i$ is importing. $t_{i, x, n}$ is the tariff that importing country $i$ imposes on imports of six digit HS product $n$ from the exporting country $x ; m_{i, x, n}$ are imports of six digit HS product $n$ of country $i$ from country $x$; and $\eta_{i, n}$ is the import demand elasticity of product $n$ in country $i$. Import demand elasticities were borrowed from Kee, Nicita and Olarreaga (2008).

The OTRI is calculated in the same way but instead of using only tariffs, we use the sum of tariffs and ad-valorem equivalents of NTM provided by Kee, Nicita and Olarreaga (2009).

To estimate the welfare effects of trade protection, we need to transform TTRI and $O T R I$ into price changes. For TTRI, assuming perfect transmission of tariff changes to domestic prices, we have:

$$
\Delta \ln p_{g}=\frac{\Delta T T R I_{g}}{1+T T R I_{g}}=\frac{-T T R I_{g}}{1+T T R I_{g}}
$$

where the last equality follows from the assumption of full elimination of tariffs (so that $\Delta T T R I_{g}=-T T R I_{g}$ ). A similar expression can be derived for OTRI. These measures capture the price changes caused by each country's own trade policy on good $g$.

We are also interested in estimating the pro-poor bias of protection abroad. To calculate the price changes brought about by this type of protection, we assume that the target countries face bilateral preferences with their trade partners and that they are small in 
world trade. Both assumptions are plausible. First, the African countries in our sample are indeed small in world trade and thus are unlikely to affect international prices. Second, most African countries have enjoyed some type of preferential access to major markets in the developed world via GSP, AGOA, EBAs, EPAs, and so on. Our assumptions imply that we can approximate the changes in the domestic price one to one with the change in foreign market access (i.e., the change in tariffs abroad is directly reflected in domestic prices). ${ }^{12}$

First, we estimate indices of the trade restrictiveness imposed by the rest-of-the-world on each country's export bundle at the different level of disaggregation of our homogenous goods classification. As in the case of "own" trade policies, we build two indices, labeled as the MA-TTRI and the MA-OTRI where MA stands for market access. More formally, MA-TTRI is given by:

$$
M A-T T R I_{i, g}=\sum_{x, n \varepsilon g} t_{i, x, n} \frac{e_{i, x, n} \eta_{i, n}}{\sum_{x, n \varepsilon g} e_{i, x, n} \eta_{i, n}}
$$

where the subscripts are defined as before, but the tariff and the import demand elasticity are now those of the partner country and $e_{i, x, n}$ are the exports of HS- $g$ for goods, $n$ for goods at the tariff line level within each good $g, i$ for the exporting country in SSA, and $x$ for the destination country. That is, the MA-TTRI is the average tariffs that an aggregated good $g$ (composed of products $n$ ) originating from country $i$ face when exported to $x$. The MA-OTRI is calculated in the same way, but instead of using tariffs in the rest-of-the-world, we used the sum of tariffs and ad-valorem equivalents of NTMs in the rest-of-the-world.

Once we have estimates of $\mathrm{MA}^{-\mathrm{TTRI}_{g}}$, we calculate the price change of good $g$ under a unitary pass-through elasticity assumption. The trade policy scenario that we study is the full elimination of protection on SSA's export bundle, or in other words, a situation where

\footnotetext{
${ }^{12}$ Abandoning these assumptions would require us to estimate the impact that the trade policy of every country in the world has on world prices, and this would involve having a model for the functioning of world markets. See Hoekman and Olarreaga (2008) for an illustration of such a model with applications to various countries around the world.
} 
the $\mathrm{MA}-\mathrm{TTRI}_{g}$ goes to zero. In consequence, the price change is given by: ${ }^{13}$

$$
\Delta \ln p_{g}=\frac{\Delta M A-T T R I_{g}}{1+M A-T T R I_{g}}=\frac{M A-T T R I_{g}}{1+M A-T T R I_{g}}
$$

This measure captures the percentage change in prices faced by producers if protection abroad on goods exported by African countries were to be eliminated. We also calculate price changes using the protection implied by the $\mathrm{MA}-\mathrm{OTRI}_{g}$ index. Note that the sums in (10) and for MA-OTRI are done over all trading partners, but they can easily be decomposed to assess the impact of the most important trading partners.

Table 7 provides the values of MA-OTRI, MA-TTRI, OTRI and TTRI for all goods, for agriculture and food products, and for other goods. Interestingly, for most African countries, the level of trade restrictiveness faced on their exports by the trade policies of the rest-of-the-world is larger than the level of trade restrictiveness they impose on their imports. This is mainly driven by non-tariff barriers, in particular non-tariff barriers imposed on their exports of agricultural and food products. ${ }^{14}$ Overall, the measure of trade restrictiveness shows quite a bit of heterogeneity even at this level of aggregation which suggests that different countries may be affected differently by trade reforms at home and abroad. For instance, Côte d'Ivoire has the highest OTRI for own protection, at around 17 percent. Note that this is partly due to the quality of its NTM data relative to other countries. Indeed, Côte d'Ivoire has the lowest level of TTRI restrictiveness (tariffs only). SSA's own protection tends also to be higher in agricultural and food products (except in Gambia and Madagascar), but when it is higher the differences between the level of restrictiveness between agriculture and other goods is much smaller than the differences in trade restrictiveness faced by SSA exporters in the rest-of-the-world. The trade restrictiveness faced by Côte d'Ivoire, Ethiopia and Madagascar in the rest-of-the-world jumps from less than 3 percent to around 20 percent once we include measures of the restrictiveness of non-tariff barriers faced abroad.

\footnotetext{
${ }^{13}$ Assuming as mentioned above that protection in the rest-of-the-world on goods imported from elsewhere is unchanged and that these SSA countries are not too large to satisfy demand in any of rest-of-the-world countries at existing domestic prices.

${ }^{14}$ Note that the measures of non-tariff barriers for SSA are not available for all products and all SSA countries.
} 
Cameroon is the least affected by protection abroad with an average restrictiveness captured by MA-OTRI at 9 percent. All other countries face levels of protection of around 20 percent. This is mainly driven by Agricultural and Food, which bear levels of protection that are generally 5 or 6 times larger than the levels of protection faced in manufacturing. The very

high levels of protection faced abroad in agriculture and food are again mainly driven by NTMs. In other goods NTMs play a role but its overall impact is much smaller.

\subsection{The Wage-Price Elasticities}

The "wage-price elasticities", the change in wages in response to changes in prices, are key parameters of the pro-poor bias of trade policy given by equation (5). In the literature, these elasticities are typically recovered by exploiting either the time series variation or the regional variation in prices and wages (Deaton, 1997; Nicita, 2009; Porto, 2006; Porto, 2010; Ravallion, 1990). In the case of SSA, this information is, however, not available. For this reason, here we propose a method to estimate price elasticities of labor income that does not require datasets with time variation in wages and prices. This is a novel method to estimate the price elasticity of wages and it is one of the main contributions of our paper. It utilizes data that is readily available and is thus much more accessible than the time-series or regional data used so far. In addition, our method allows for the estimation of wage-price elasticities at the 6-digit level of the HS. This rich heterogeneity will allow us, in turn, to exploit the detailed microdata in the household surveys when computing the pro-poor bias of trade policy.

The model, which builds on the GDP (or revenue) function approach, is based on Kee, Nicita and Olarreaga (2008) adaptation of Kohli (1991) and Harrigan (1997) setup. We assume that the GDP function is common across all countries up to a country-specific term, which controls for country productivity differences. Let $G(\mathbf{p} ; \mathbf{v})$ be this well defined GDP function, which depends on a vector of prices for goods $(\mathbf{p})$ and endowments $(\mathbf{v}) . G(\mathbf{p} ; \mathbf{v})$ is twice differentiable and it is convex in $\mathbf{p}$ and concave in $\mathbf{v}$. Then by Young's theorem we 
have that:

$$
\frac{\partial^{2} G}{\partial p_{n} v_{m}}=\frac{\partial^{2} G}{\partial v_{m} p_{n}}
$$

where $p_{n}$ is price of good $n$ (at the HS 6-digit tariff line level) and $v_{m}$ is factor endowment $m$. By the envelope theorem we know that $\partial G / \partial p_{n}=q_{n}$, where $q_{n}$ are quantities of good $n$, and $\partial G / \partial v_{m}=w_{m}$, where $w_{m}$ is the price of factor endowment $m$. Thus, we have:

$$
\frac{\partial q_{n}}{\partial v_{m}}=\frac{\partial w_{m}}{\partial p_{n}}
$$

The left-hand-side of equation (13) is the Rybczynski effect: it measures the change in output at the product level for a given change in factor endowments; the right-hand-side is what we are after, i.e., the change in wages following a given change in prices. To capture the important variance in trade policy at the tariff line level, we would like to estimate these wage elasticities at the most disaggregated possible level. Thus, instead of working with production data as in Harrigan (1997), we adopt the Kee, Nicita and Olarreaga (2008) approach and use imported goods instead, assuming that they are inputs to the production of other goods. In the case of exported goods, we assume that they are imperfect substitutes to domestically produced goods (i.e., $q_{n}$ will appear with a negative sign in the GDP function when the good is imported - as all imported goods are assumed to be inputs into the production process,- - and a positive sign when we are estimating the reaction of wages to exported prices, or rather exports to changes in labor endowment).

To implement the above GDP function empirically, we approximate $G(\mathbf{p} ; \mathbf{v})$ with a flexible translog functional form with respect to prices and endowments:

$$
\begin{aligned}
\ln G(\mathbf{p}, \mathbf{v}) & =a_{00}+\sum_{n} a_{0 n} \ln p_{n}+\frac{1}{2} \sum_{n} \sum_{k} a_{n k} \ln p_{n} \ln p_{k}+ \\
& +\sum_{m} b_{0 n} \ln v_{m}+\frac{1}{2} \sum_{m} \sum_{\lambda} b_{m \lambda} \ln v_{m} \ln v_{\lambda}+\sum_{n} \sum_{m} c_{n m} \ln p_{n} \ln v_{m}
\end{aligned}
$$

where $a, b$ and $c$ are the translog parameters, and subscript $k$ (like $n$ ) is for six-digit HS goods. Ensuring that the GDP function satisfies all the classic homogeneity and symmetry 
restrictions, the derivative of the GDP function with respect to prices yields the share of good $n$ (and imported or exported good in our case) in GDP:

$$
s_{n}=\frac{p_{n} q_{n}}{G D P}=a_{0 n}+a_{n n} \ln p_{n}+\sum_{k \neq n} a_{n k} \ln p_{k}+\sum_{m} c_{n m} \ln v_{m}
$$

Our parameter of interest is $c_{n m}$ which captures the Rybczynski effect of changes in factor endowment $m$ on imports (or exports) of good $n$. The derivative of $s_{n}$ with respect to factor endowment $v_{m}$ is given by:

$$
\frac{\partial s_{n}}{\partial v_{m}}=\frac{p_{n}}{G} \frac{\partial q_{n}}{\partial v_{m}}-\frac{s_{n}}{G} \frac{\partial G}{\partial v_{m}}=c_{n m} \frac{1}{v_{m}}
$$

Solving the last equality for $\partial q_{n} / \partial v_{m}$, and noting that by the envelope theorem $\partial G / \partial v_{m}=$ $w_{m}$, yields:

$$
\frac{\partial q_{n}}{\partial v_{m}}=\frac{1}{p_{n}}\left[c_{n m} \frac{G}{\partial v_{m}}+s_{n} w_{m}\right]=\frac{w_{m}}{p_{n}}\left[\frac{c_{n m}}{s_{m}}+s_{n}\right]
$$

where $s_{m}$ is the share of factor income $m$ in GDP. Since $\partial q_{n} / \partial v_{m}=\partial w_{m} / \partial p_{n}$, it follows that the elasticity of the wage of factor $m$ with respect to prices of good $n$ is given by:

(18) $\varepsilon_{w_{m} p_{n}}=\frac{c_{n m}}{s_{m}}+s_{n}$

Thus with data on the share of good $n$ in GDP (which is nonpositive for imported goods and positive for exported goods) which we take from United Nation's Comtrade, and on the share of unskilled labor and skilled labor income in GDP (which is drawn from the household surveys), as well as an estimate of $c_{n m}$, we can then provide our estimate of the price elasticity of unskilled and skilled wages for different 6-digit HS goods.

Note that $c_{n m}$ (the parameter of the GDP function) can be positive or negative depending on good $n$ factor intensity, but its value and sign is common across all countries. When $c_{n m}$ is positive, this implies that an increase in the labor endowment $\left(v_{m}\right)$ will lead to a reduction in imports of good $n$ (given that $s_{n}$ is negative when considering imports). This implies that 
good $n$ is labor intensive. However, the wage elasticity will vary by country according to each country's labor abundance and the importance of imports of good $n$ in GDP.

To obtain values for $c_{n m}$, we estimate equation (15) for both imports and exports of each HS-6 digit good assuming that all goods imported or exported are homogeneous. This allows us to replace the world price of each HS-6 digit good by a year dummy (given that we estimate these equations for each HS-6 digit good separately). Given that the share equation in (15) depends on domestic prices and not on world prices, we also introduce country dummies to control for what we assume is time invariant trade policies which will affect domestic prices. ${ }^{15}$ We do not directly introduce trade policy because the available time series are only available for a few countries before the late 1990, and even fewer are located in SSA. We then introduce as factor endowments capital, arable land, unskilled labor and skilled labor. Arable land is from the World Development Indicators. Capital is constructed from World Development Indicators' investment data using the permanent inventory method. Skill and unskilled labor data is from the Barro and Lee database. Endowment variables are divided by land, to ensure constant returns to scale. The sample spans from 1988 when the HS was introduced to 2009, and covers all six SSA countries.

Thus, we estimate $c_{n m}$ across countries $(i)$ for each HS-6 digit good $n$ with ordinary least squares using the following specification first for exports and then for imported goods:

$$
s_{i, t}=a_{i}+a_{t}+\sum_{m} c_{n m} \ln v_{m, i, t}+\varepsilon_{i, t}
$$

And then use (18) to compute the price elasticities of wages for unskilled labor and skilled labor for both exported and imported goods. The average elasticities for changes in export and imported prices at the six digit of the HS for each country are given in Table 8. All average elasticities are negative and very small, but this hides some significant variation across goods and within countries, as shown by the very large standard deviation relative to the mean elasticity in each country. The fact that the average elasticity is very small is to be expected as we are considering changes in prices of goods at the six digit of the HS. The

\footnotetext{
${ }^{15}$ See Harrigan (1997) for similar assumptions when estimating Rybczynski elasticities.
} 
average share of imports and exports of an HS 6 digit good in the economy is very small, and therefore changes in their prices should only lead to small changes in wages.

Interestingly the correlation between unskilled and skilled wage elasticities is equal to -0.54 (both on the export and import side), and statistically significant at the 1 percent level. This means that when the elasticity of unskilled wages increases when moving from one HS 6-digit good to another, the elasticity of skilled wages tend to fall. This suggests that skilled and unskilled wages are likely to move in opposite direction in the presence of trade reforms.

We can also check the share of "natural enemies" as defined by Jones and Scheinkman (1977). A natural enemy of unskilled labor, for example, is a good for which the price elasticity of unskilled wages is negative. That is, when the price of that good increases (through trade policy for example), the price of unskilled labor falls. Among imported goods, on average 58 percent of HS 6-digit goods are natural enemies of unskilled labor; it varies between 55 percent in Cameroon and 60 percent in Gambia. And only 45 percent of HS 6-digit imported goods are natural enemies of skilled labor; it varies between 43 percent in Côte d'Ivoire and 46 percent in Ethiopia.

More importantly, we are not interested in the price elasticities of wages per se, but rather in how the elimination of all trade protection would affect unskilled and skilled wages (third term in equation (5)). We then compute:

$$
\widehat{w}=\sum_{g} \varepsilon_{w p_{g}} d \ln p_{g}
$$

The percentage change in (unskilled or skilled) wages is simply given by the sum across all goods of the product of price elasticities of wages and price changes associated with the elimination of trade protection. To capture the elimination of home protection, we make $d \ln p_{g}$ equal to $-T T R I_{g} /\left(1+T T R I_{g}\right)$ or $-O T R I_{g} /\left(1+O T R I_{g}\right)$ and we use the price-wage elasticities estimated using import data. If we were to consider the elimination of protection abroad we need to replace TTRI and OTRI by MA-TTRI and MA-OTRI, and the price-wage elasticities would need to be replaced by the ones estimated using export 
data and equation (19). Thus, the set of goods over which the sum is taken depends on whether we are considering protection at home or protection abroad.

Results for the estimation of the percentage change in unskilled and skilled wages that would follow the elimination of existing levels of trade protection at home and abroad are reported in Table 9. They show that the impact of the restrictiveness of SSA's own trade policy on wages seems to be more important than the impact of the restrictiveness of the rest-of-the-world trade policies on SSA's wages. The average percentage change in wages is much larger when looking at SSA's own trade policy. This may seem surprising given that overall levels of protection faced by SSA exporters are higher than the levels of protection at home, as can be seen in Table 7. But this finding can be partly explained by the fact that wage elasticities estimated with import data are higher than those estimated with export data. In turn, this is because exports tend to be concentrated in the agricultural sector, and employment may be less sensitive to variations in agricultural prices than in manufacturing prices for technology reasons. Another explanation is that the covariance between domestic trade policy and the wage elasticities is higher than the covariance between the rest-of-the-world trade policies and the wage elasticities due to political economy considerations. Indeed, domestic tariffs may be chosen in order to maximize the impact on domestic overall wages for political reasons leading to a strong correlation between levels of protection and the sensitivity of wages to changes in prices. This mechanism is absent in the case of rest-of-the-world protection, which is determined by political economy factors in foreign countries.

More interestingly, we found strong Stolper-Samuelson type effects associated with SSA's own trade policy. That is, the elimination of SSA's trade protection would lead to a relative increase in unskilled wages. In other words, the existing structure of protection in SSA favors skilled over unskilled workers. This is in part because import-competing sectors tend to be relatively more skilled-intensive in SSA for comparative-advantage reasons, and in part because the political economy of SSA countries may tend to be biased in favor of skilled-workers. This is contrary to what was found by Hanson and Harrison (1999) for Mexico, where protection before the 1985 reforms tended to be biased in favor of unskilled 
workers, but one important difference between Mexico in 1985 and the six SSA countries in our sample is the degree of democracy. The influence of political economy forces on the structure of protection may well depend on the extent to which voter's preferences are in policymaker's decisions. ${ }^{16}$

More generally, the result that the elimination of trade protection leads to an increase in unskilled wages is somehow at odds with most of the existing empirical literature on the impact of trade liberalization on wages in developing countries, which shows that tariff liberalization leads to relative increases in skilled wages (Galiani and Sanguinetti, 2003, Goldberg and Pavcnik, 2004, 2005 and 2007, Revenga, 1997 or Robertson, 2004). Note that there are some important exceptions such as Gonzaga, Menezes Filho and Terra (2006) who found Stolper-Samuelson effects in Brazil after controlling for the relative size of the import competing sector. And Galiani and Porto (2010) recently found Stolper-Samuelson effects in Argentina's trade reforms after introducing general equilibrium type effects in a literature which has previously mainly identified the impact of trade protection on wages by exploring the correlations at the industry level. Their general equilibrium result are consistent with what we obtained for the six SSA countries in our sample within a very different framework, but which also allows for general equilibrium effects. ${ }^{17}$

When it comes to the impact of rest-of-the-world's trade policy on SSA's wages, effects are smaller, and do not necessarily tend to show Stolper-Samuelson type effects with only half of the countries experiencing an increase in the ratio of unskilled to skilled wages when the rest-of-the-world eliminates the trade restrictions it imposes on SSA's export bundle. This more ambiguous result on the export side could be partly explained by the fact that price shocks to which SSA exporters are exposed reflect the structure of protection in the rest-of-the-world, which may tend to protect more skilled jobs, and therefore may benefit skilled workers more than what would have been expected by a simple Stolper-Samuelson prediction.

\footnotetext{
${ }^{16}$ See for example, Milner and Kubota (2005).

${ }^{17}$ Other explanations for the lack of impact of trade reforms on wages and employment, or an increase in the relative wage of skilled workers in countries which are unskilled labor abundant have to do with simultaneous capital account liberalization or opening to foreign direct investment. See for example, Feenstra and Hanson (1997) who argued that labor demand of foreign firms in Mexico tends to be biased towards skilled workers.
} 


\section{Results}

We first discuss the results obtained using the index of pro-poor bias, and then turn to the non parametric regression of changes in household welfare and household income. We always start presenting the evidence regarding the changes in welfare following the elimination of each SSA country's own trade policy and then turn to the impact following the elimination of ROW's trade policy on each SSA country's export bundle. We also distinguish between changes following the elimination of tariffs only (TTRI and MA-TTRI), and the elimination of both tariffs and NTMs (OTRI and MA-OTRI).

Table 10 shows the results of the computation of the index of pro-poor bias given by equation (7) associated with the elimination of both tariffs and NTM. The index is computed by taking the difference in average welfare at the top and bottom 40 percent of the income distribution. We later check the robustness of results for the top and bottom 20 and 10 percent of the income distribution. The first four columns show the index associated with the elimination of each SSA country's own trade policy. The last three columns show the index associated with the elimination of trade barriers imposed by the rest-of-the-world on SSA's export bundle. In the case of own trade policies, the first column, labeled overall, provides the value of the index of pro-poor bias, and the following three columns decompose the overall impact into an expenditure, sales and wage effect as in (??). In the case of rest-of-the-world's trade policies, the first column provides the value of the index of pro-poor bias, and the following two columns provide the decomposition into sales and wages effects. ${ }^{18}$ Let us recall that a positive value indicates that the elimination of trade barriers benefited more rich households than poor households. In other words, the existing trade policy is pro-poor, as removing it leads to a larger increase in the income of households at the top of the income distribution. A negative value, on the other hand, indicates that the existing

\footnotetext{
${ }^{18}$ In the case of rest-of-the-world's trade policies, there is no expenditure effect, because as discussed in the previous section we assume that the improvement in market access is preferential and therefore only producer prices are affected by the elimination of trade barriers on each SSA country export bundle. Indeed when a large partner provides preferential access to domestic producers this only affects the price received by producers, but leaves consumer prices unchanged (see Richardson, 1995). The latter are still determined by the unchanged world price and the unchanged domestic trade barrier if any. In any case, if we were to include the consumption effect when computing the pro-poor bias for trade policies in the rest-of-the-world the correlation with the results reported in Table 10 is around 0.70 .
} 
trade policy is pro-rich.

In interpreting these indexes, keep in mind that they combine, in each country, the patterns of income shares (from Table 5) and expenditure shares (from Table 6) with the structure of protection (from Table 7). In consequence, it is in principle not possible to decompose which part of the index is due to expenditure and income structure and which to tariff protection structure. It is the covariance between the structure of protection and consumption and income shares that drives the contribution of each element to the index. ${ }^{19}$

In all countries the index takes a positive value, indicating that the existing trade policy has a pro-poor bias, except in Ethiopia. The elimination of the existing structure of protection would bring larger benefits to rich households than to poor households. The largest pro-poor bias is to be found in Gambia, where the elimination of the existing trade barriers would bring a change in rich households' income which is 4.72 percentage points larger than the change in the real income of poor households. Only Ethiopia shows a mild pro-rich bias with the change in rich households' income being less than half a percentage point smaller than the change in the real income of poor households. In all countries the index is driven by the production effect (agricultural sales channel), which is strongly pro-poor, except in Ethiopia. The contribution of the labor income channel (wages) on the pro-poor bias index is relatively small, even though it is always negative, suggesting that existing trade policy tends to be pro-rich through this channel. Again, this is consistent with Stolper-Samuelson type effects. The fact that the contribution of the labor income channel to the overall indicator is relatively modest, in spite of the strong Stolper-Samuelson wage effects reported in Table 9, can be partly explained by the fact that the share of unskilled labor income at the top 40 percent of the income distribution is quite similar to the share at the bottom 40 percent, whereas there are larger differences in agricultural sales and consumption shares (see Table 5).

Indeed the pro-rich bias of the existing trade policies through the labor income channel is more than compensated in most countries by a strong pro-poor bias through the agricultural

\footnotetext{
${ }^{19}$ It is straightforward to show that the indicator of pro-poor bias is given by the covariance of the structure of protection with the net "sales" of rich and poor households, where net "sales" are determined as the difference in between income and expenditure of rich and poor households on each good.
} 
sales channel. In other words, in most SSA countries the elimination of their trade protection would redistribute income towards poor households through the labor income channel, but redistribute income away from poor households through the agricultural sales channel. The only exception is Ethiopia where there is a small pro-rich bias through the agricultural sales channel, which complements the pro-rich bias through the labor income channel.

The contribution of the consumption channel to the pro-poor index is ambiguous. The consumption effect tends to be pro-poor in Burkina-Faso and Gambia, but pro-rich in the other four countries. This is partly explained by the fact that a large share of the expenditure of poor households is not affected by trade reforms (autoconsumption for example). More importantly, the production effect is always larger (in absolute value) than the consumption effect, suggesting again that the overall index is dominated by the production effect, which is pro-poor, except in Ethiopia.

When it comes to the trade barriers that the rest-of-the-world imposes on SSA export bundle, in four of the six countries the index takes a negative value, suggesting that the elimination of rest-of-the-world's trade barriers on SSA exports would tend to benefit more poor than rich households. There is therefore a pro-rich bias in the existing trade policy of the rest-of-the-world. The exceptions are Burkina Faso and Ethiopia where existing rest-of the-world's trade policies tend to have a pro-poor bias. The values of the index are mainly driven by household agricultural sales again, as the wage effect does not seem to be very different across rich and poor households.

Table 11 provides the same computations but using tariffs only. The indices tend to have the same sign as before and are generally smaller, simply reflecting that the distortions introduced by tariffs are obviously smaller than the distortions induced by both tariffs and NTMs. This is particularly the case for trade policies imposed by the rest-of-the-world. Indeed, most SSA countries enjoy duty free access to their trading partners markets either through regional agreements or unilateral preferences granted by most developed countries under GSP type schemes, such as Everything But Arms or AGOA. These schemes, however, for the most part do not address non-tariff barriers, and results in Table 10 tend to suggest that these are generally biased against poor households. 
As a robustness check we also compute the overall pro-poor bias index for the top and bottom 20 and 10 percent. Results are reported in Table 12. The first three columns report the value of the index for the elimination of own trade policies, and the last three columns the value of the index for the elimination of rest-of-the-world's trade policies on SSA's export bundle. The signs of the pro-poor bias indices are identical regardless of whether we take a 40, 20 or 10 percent threshold, with the exception of Gambia and its partners' trade policies, where the index increases marginally but changes sign, and of Côte d'Ivoire's own trade policies which also changes signs when we take a 10 percent criteria). The value of the index tends to increase (although not always) as we move towards the extreme of the income distribution, but the differences are generally not very large.

Because of these few changes in signs in Table 12, we check whether our index of pro-poor bias misses some interesting heterogeneity within rich and poor households, that could be illustrated with plots of non-parametric regressions of household income on changes in real income following the elimination of each SSA country's own trade policy or the elimination of the rest-of-the-world's trade barriers on their export bundle. Figure 1 provides these plots by country. A negative slope for the non-parametric regressions suggests that the poor benefit more than the rich from the elimination of the existing trade policy, and therefore the existing trade policy is pro-rich. A positive slope suggests that the rich benefit more than the poor from the elimination of the existing trade policy, and therefore the existing trade policy is pro-poor. The local regressions are estimated for changes in real income following the elimination of both tariffs and NTMs. We also report the non-parametric estimation of income distribution in each of these countries to assess the relative importance of some of the non-monotonicities in the two non-parametric regressions.

Results broadly confirmed the results reported in Tables 10 and 12. In Gambia the strong pro-poor bias of their trade policy is also confirmed by a monotonically increasing curve. In Côte d'Ivoire the pro-poor bias is also confirmed, but the relationship is non-monotonic, and peaks for middle income households who experience the largest increases in household income following the removal of their own protection, explaining the change in sign for own trade policy observed in Table 12 There are also some non-monotonicities in Ethiopia and 
Burkina Faso.

\section{Conclusions}

Trade reforms affect different households differently, depending on individual preferences and factor endowments. This paper disentangles the impact of trade policy reforms on SSA's poor households. To this end, we start with a simple but well established framework (Winters et al., 2004) and propose an extension to include adjustments in labor income, that does not require time series of household data.

Our objective is to measure the potential pro-poor bias in the trade policy of six SSA countries, as well as in the trade policies of their trading partners. Our index of pro-poor bias is given by the difference in the percentage welfare changes for rich and poor households associated with the elimination of trade barriers. A large and positive value of the index indicates that rich households tend to benefit more from the removal of trade barriers than poor households in percentage terms, and therefore it is an indication of a pro-poor bias in existing trade policies. Similarly, a negative value indicates that the poor benefit relatively more than the rich from the elimination of trade barriers and therefore is an indication of a pro-rich bias in the existing structure of protection. We calculate these indices for two different shocks: first, the elimination of SSA's own trade policies, and then the elimination of trade policies by SSA's trading partners.

Results suggest that SSA's own trade policies are pro-poor, with the exception of Ethiopia whose trade policy shows a mild pro-rich bias. The countries with the strongest pro-poor bias in their existing structure of trade protection are Gambia and Côte d'Ivoire. On the other hand, the elimination of trade polices imposed by SSA's trading partners on SSA export bundle tends to be pro-rich. Removing the protection in the rest-of-the-world will bring larger increases in welfare for poor than rich households in all countries, except Ethiopia and Burkina-Faso. In the case of rest-of-the-world's trade polices, the effects are mainly driven by non-tariff measures in the rest-of-the-world, partly because most SSA countries benefit from generous tariff preferences in their main export markets. Addressing the restrictiveness 
of non-tariff measures in SSA's trading partners will help not only SSA exporters, but more importantly, the poorest households in SSA.

It is important to note that a positive value of the index of pro-poor bias only signals that the existing trade policy is pro-poor, i.e., that the poor benefit relatively more or are hurt relatively less than the rich by the existing structure of protection. It does not imply that the poor will be better off. Indeed in some cases, even though there is a strong pro-poor bias in the existing structure of protection, the welfare of the poor may be lower than in the absence of trade barriers.

To conclude, Africa's own trade policy tends to redistribute income from rich to poor households, and is thus pro-poor. Trade barriers imposed by the rest-of-the-world on SSA's export bundle, in particular NTM, tend to redistribute income from poor to rich households, and are thus pro-rich. What can explain this? An important part of the answer is agricultural protection, which is high both in SSA and in the rest-of-the-world. High levels of protection in agriculture in SSA tend to hurt the poor relatively less than the rich because net production of agricultural goods by poor household is larger than for rich households. At the same time, higher levels of agricultural protection in the rest-of-the-world tend to be biased against poor households because they lead to lower agricultural prices which are more costly for poor households which have a larger net production of agricultural goods. This implies that the neglect of the agricultural sector by the GATT during many rounds of tariffs (but more importantly non-tariff) negotiations has had ambiguous effects on SSA's poor households/farmers. While better market access, through the current Doha round would benefit the poor more than the rich in SSA, the simultaneous elimination of own trade policies may bring smaller gains for the poor, or hurt SSA's poor relatively more than rich households. 


\section{References}

Anderson, J. and P. Neary (2005). Measuring the Restrictiveness of Trade Policy, Boston: MIT Press.

Benjamin, D. (1992). "Household Composition, Labor Markets, and Labor Demand: Testing for Separation in Agricultural Household Models," Econometrica, vol. 60, No.2, pp. 287-322.

Coello, B., M. Fall and A. Suwa-Eisenmann (2011), "Trade liberalization and poverty dynamics in Vietnam 2002-2006", mimeo, INRA, Paris School of Economics.

Deaton, A. (1989). "Rice Prices and Income Distribution in Thailand: a Non-parametric Analysis," Economic Journal, 99 (Supplement), pp. 1-37.

Deaton, A. (1997). The Analysis of Household Surveys - A Microeconometric Approach to Development Policy. Baltimore: Johns Hopkins Press.

Feenstra, R., and G. Hanson, 1997. Foreign direct investment and relative wages: evidence from Mexicos maquiladoras. Journal of International Economics 42, 371394.

Francois, J. and H. Rojas-Romagosa (forthcoming), "Household welfare, social inequality and trade," Journal of Development Economics.

Galiani, S., and P. Sanguinetti (2003), "The Impact of Trade Liberalization on Wage Inequality: Evidence from Argentina," Journal of Development Economics 72, 497513.

Galiani, S. and G. Porto (2010), "Trends in tariff reforms and in the structure of wages," Review of Economics and Statistics 92(3), 482-494.

Goldberg, P. and M. Knetter (1997). "Goods Prices and Exchange Rates: What Have We Learned?," Journal of Economic Literature, vol. XXXV, pp. 1243-1272.

Goldberg, P., and N. Pavcnik (2004). "Trade, Inequality, and Poverty: What Do We Know? Evidence from Recent Trade Liberalization Episodes in Developing Countries," Brookings Trade Forum 2004, 223269. 
Goldberg, P., and N. Pavcnik (2005). "Trade, Wages, And The Political Economy Of Trade Protection: Evidence From The Columbia Trade Reforms," Journal of International Economics, 66(1), 75-105.

Goldberg, P., and N. Pavcnik (2007). "Distributional Effects of Globalization in Developing Countries," Journal of Economic Literature 45:1, 3982.

Gonzaga, G., Menezes Filho, N. and C. Terra (2006), "Trade liberalization and the evolution of skill earnings differentials in Brazil," Journal of International Economics 68(2), 345-367.

Hanson, G., and A. Harrison, A. (1999). "Trade and wage inequality in Mexico". Industrial and Labor Relations Review 52(2), 271288.

Harrigan, J. (1997). "Technology, Factor Supplies, and International Specialization: Estimating the Neoclassical Model," American Economic Review 87, 475-494.

Harrison, A. and G. Hanson (1999). "Who gains from trade reforms? Some remaining puzzles, Journal of Development Economics 59, 125-154.

Hoekman, B. and M. Olarreaga (2008). Global Trade and Poor Nations. Washington, DC: Brookings Institution Press.

Jacoby, H. (1993). "Shadow Wages and Peasant Family Labor Supply: An Econometric Application to the Peruvian Sierra," Review of Economic Studies, 60, pp. 903-921.

Jones, R. and J. Scheinkman (1977). "The relevance of the two-sector production model in trade theory," Journal of Political Economy 85(5), 909-35.

Kee, H. L., A. Nicita and M. Olarreaga (2009). "Estimating Trade Restrictiveness Indices," Economic Journal 119(534), 172-199.

Kee, H. L., A. Nicita and M. Olarreaga (2008). "Import Demand Elasticities and Trade Distortions," Review of Economics and Statistics 90(4), 666-682.

Kohli, U. (1991). Technology, Duality, and Foreign Trade: The GNP Function Approach to Modeling Imports and Exports. Ann Arbor: University of Michigan Press. 
Krivonos, E. and M. Olarreaga (2009). "Sugar Prices, Labor Income and Poverty in Brazil," Economía 9(2), 217-245.

Le, K. (2009). "Shadow Wages and Shadow Income in Farmers' Labor Supply Functions," American Journal of Agricultural Economics, Vol. 91, Issue 3, pp. 685-696.

Milner, H. and K. Kubota (2005). "Why the move to free trade? Democracy and trade policy in the developing countries", International Organization 59, 107-143.

Nicita, A. (2009). "The Price Effect of Trade Liberalization: Measuring the Impacts on Household welfare," Journal of Development Economics, vol. 89(1), pp. 19-27.

Porto, G. (2006). "Using Survey Data to Assess the Distributional Effects of Trade Policy," Journal of International Economics 70, 140-160.

Porto, G. (2008). "Agro-manufacture Export Prices, Wages and Unemployment," American Journal of Agricultural Economics, 90(3), 748-764.

Porto, G. (2010). "International Market Access and Poverty in Argentina," Review of International Economics, May 2010.

Revenga, A. (1997). "Employment and Wage Effects of Trade Liberalization: The Case of Mexican Manufacturing," Journal of Labor Economics 15, 520543.

Richardson, M. (1995). "Tariff revenue competition in a free trade area," European Economic Review 39(7), 1429-1437.

Robertson, R. (2004). "Relative Prices and Wage Inequality: Evidence from Mexico," Journal of International Economics 64, 387409.

Singh, I., L. Squire, and J. Strauss, eds. (1986). Agricultural Household Models: Extensions, Applications and Policy. Baltimore, Johns Hopkins Press for the World Bank.

Ural Marchand, B. (2011). "Tariff Pass-Through and the Effect of Trade Liberalization on Household Welfare," mimeo University of Alberta. 
Table 1

List of Household Surveys

Sub Saharan Africa

\begin{tabular}{|c|c|c|c|c|}
\hline Country & Year & Survey & Households & $\begin{array}{l}\text { Rural } \\
\text { share }\end{array}$ \\
\hline Burkina Faso & 2003 & $\begin{array}{lll}\text { ENQUETE } & \text { BURKINABE SUR } & \text { LES } \\
\text { CONDITIONS DE VIE DES MENAGES } & \end{array}$ & 8500 & 0.69 \\
\hline Côte d'Ivoire & 2002 & ENQUÊTE NIVEAU DE VIE MÉNAGES & 10801 & 0.48 \\
\hline Cameroon & 2001 & $\begin{array}{l}\text { DEUXIEME ENQUÊTE CAMEROUNAISE } \\
\text { AUPRĖS DES MÉNAGES }\end{array}$ & 10992 & 0.35 \\
\hline Ethiopia & 2000 & $\begin{array}{l}\text { HOUSEHOLD INCOME, CONSUMPTION } \\
\text { AND EXPENDITURE SURVEY }\end{array}$ & 25861 & 0.67 \\
\hline Gambia & 1998 & HOUSEHOLD ECONOMIC SURVEY & 2085 & 0.51 \\
\hline Madagascar & 2005 & $\begin{array}{l}\text { ENQUÊTE PÉRIODIQUE AUPRÈS DES } \\
\text { MÉNAGES }\end{array}$ & 11781 & 0.50 \\
\hline
\end{tabular}

Source: World Bank Development Data Platform (DDP) and various Country Statistical Offices. 


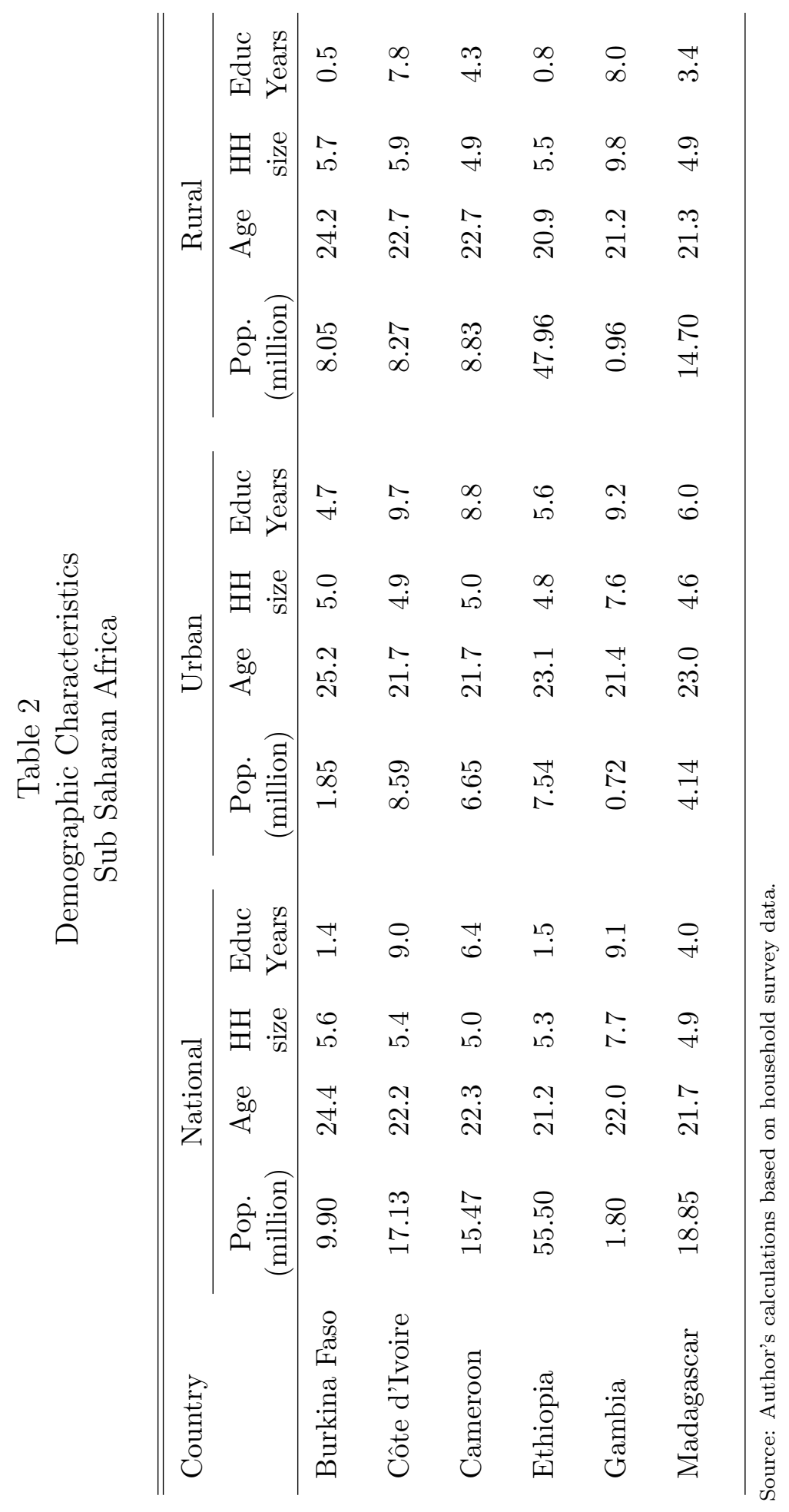




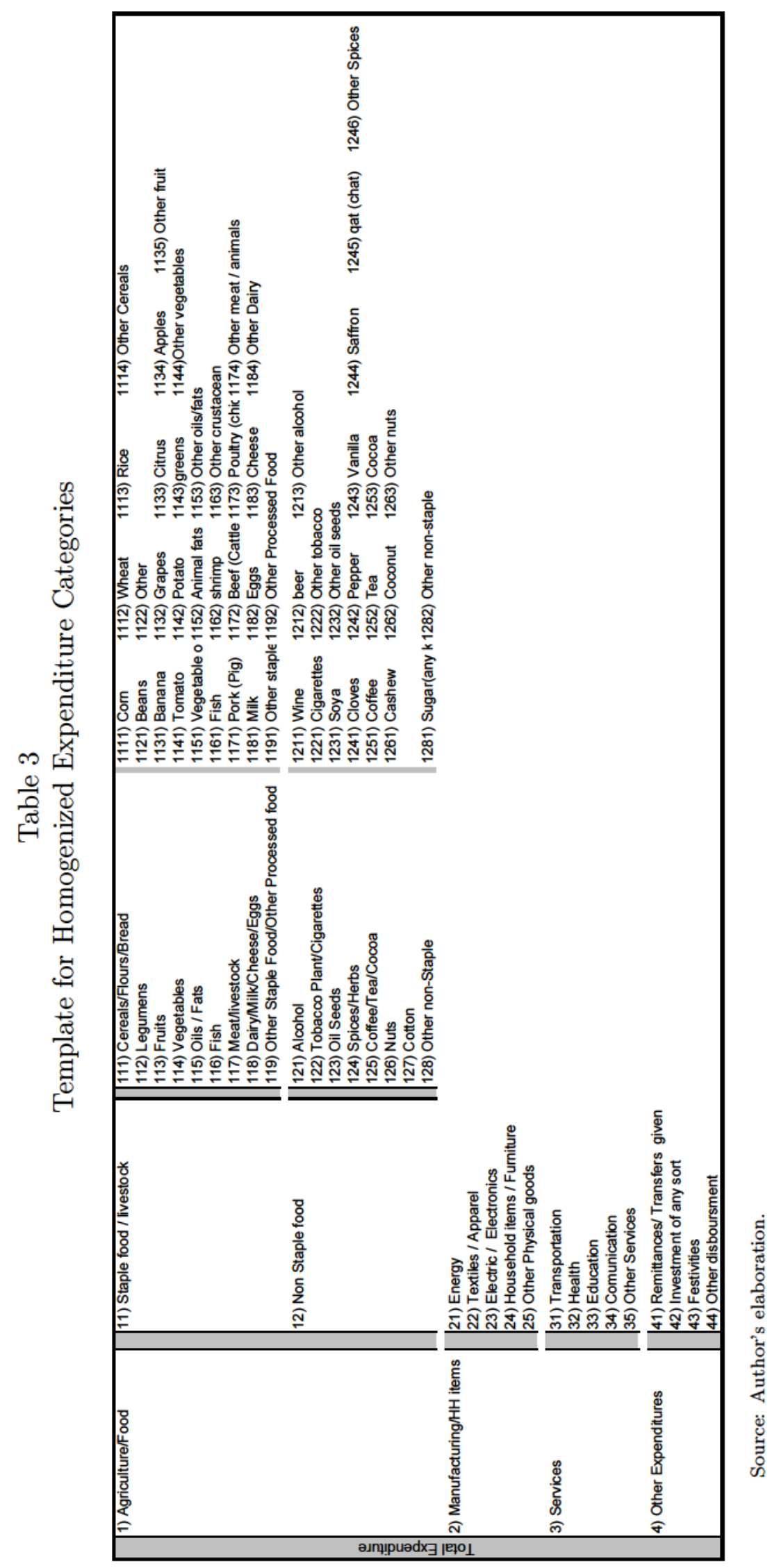




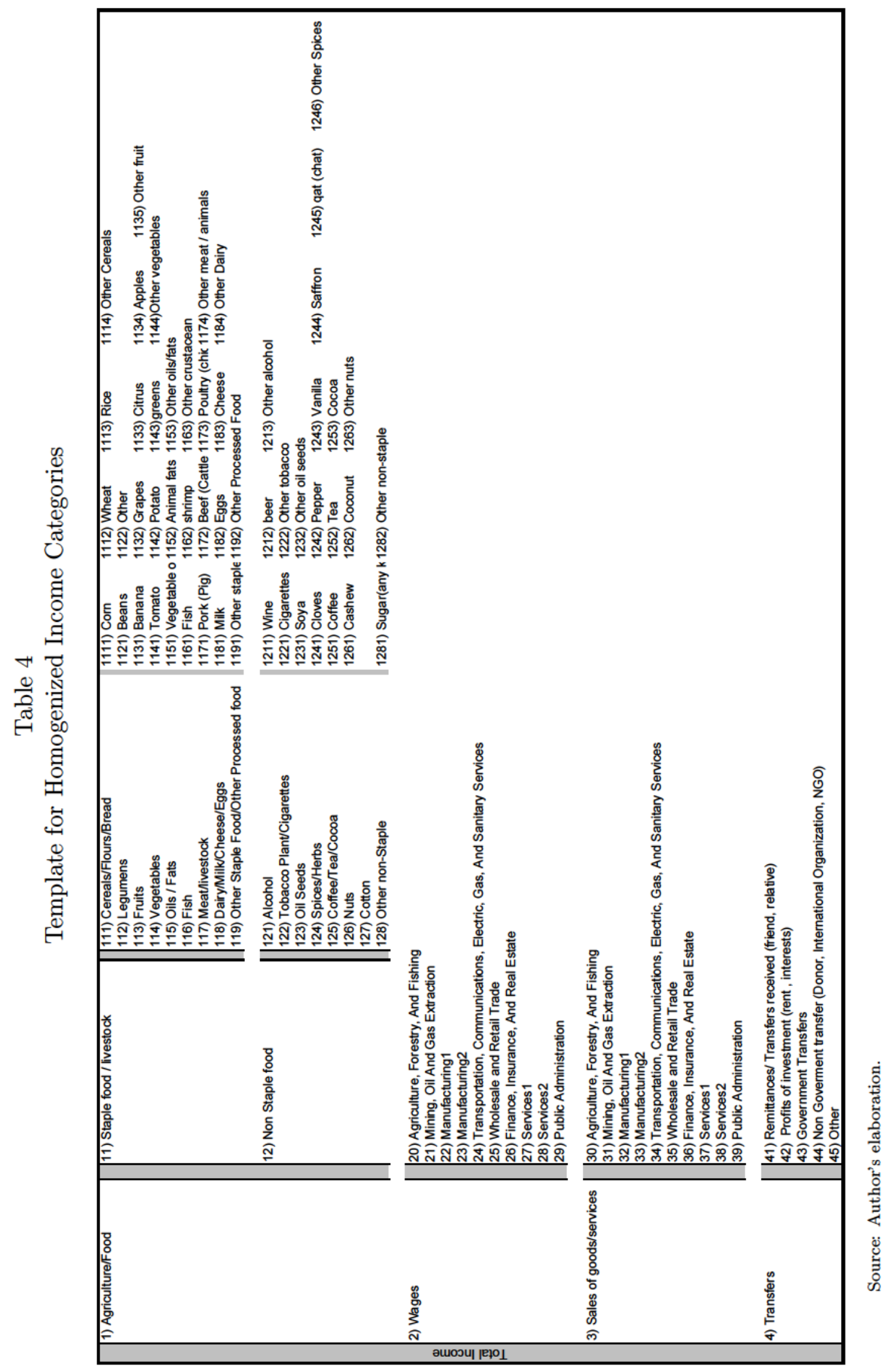


Table 5

Income Shares

\begin{tabular}{lcccccccc}
\hline \hline \multirow{2}{*}{ Country } & \multicolumn{3}{c}{ Bottom $40 \%$} & & \multicolumn{3}{c}{ Top $40 \%$} \\
\cline { 2 - 4 } \cline { 7 - 8 } & Sales & $\begin{array}{c}\text { Skilled } \\
\text { wages }\end{array}$ & $\begin{array}{c}\text { Unskilled } \\
\text { wages }\end{array}$ & & Sales & $\begin{array}{c}\text { Skilled } \\
\text { wages }\end{array}$ & $\begin{array}{c}\text { Unskilled } \\
\text { wages }\end{array}$ \\
\hline Burkina Faso & 24.1 & 0.3 & 26.5 & & 23.6 & 1.5 & 28.7 \\
Côte d'Ivoire & 51.4 & 1.0 & 22.9 & & 25.7 & 9.0 & 27.6 \\
Cameroon & 18.3 & 2.4 & 35.3 & & 9.3 & 19.8 & 33.7 \\
Ethiopia & 14.8 & 0.6 & 30.8 & & 17.0 & 9.8 & 33.0 \\
Gambia & 27.3 & 0.5 & 66.4 & & 8.2 & 4.3 & 71.2 \\
Madagascar & 34.5 & 1.0 & 33.9 & & 28.0 & 8.5 & 31.6 \\
\hline
\end{tabular}

Source: Author's calculations based on household survey data.

The category "sales" does not include sales in services or other categories that are not going to be directly affected by changes in trade policy.

A worker is defined as "skilled" if he has more than 9 years of education.

Table 6

Budget Shares

\begin{tabular}{|c|c|c|c|c|}
\hline \multirow[b]{2}{*}{ Country } & \multicolumn{2}{|c|}{ Bottom 40} & \multicolumn{2}{|c|}{ Top 40} \\
\hline & Food & Other & Food & Other \\
\hline Burkina Faso & 38.0 & 11.5 & 36.0 & 19.6 \\
\hline Côte d'Ivoire & 56.7 & 19.2 & 48.8 & 13.7 \\
\hline Cameroon & 53.6 & 16.0 & 51.6 & 18.1 \\
\hline Ethiopia & 32.9 & 13.2 & 32.1 & 20.4 \\
\hline Gambia & 53.2 & 17.4 & 65.4 & 10.7 \\
\hline Madagascar & 45.0 & 12.6 & 44.0 & 11.9 \\
\hline
\end{tabular}

Source: Author's calculations based on household survey data.

The category "other" does not include auto-consumption or expenditure in services that are not going to be directly affected by changes in trade policy. 


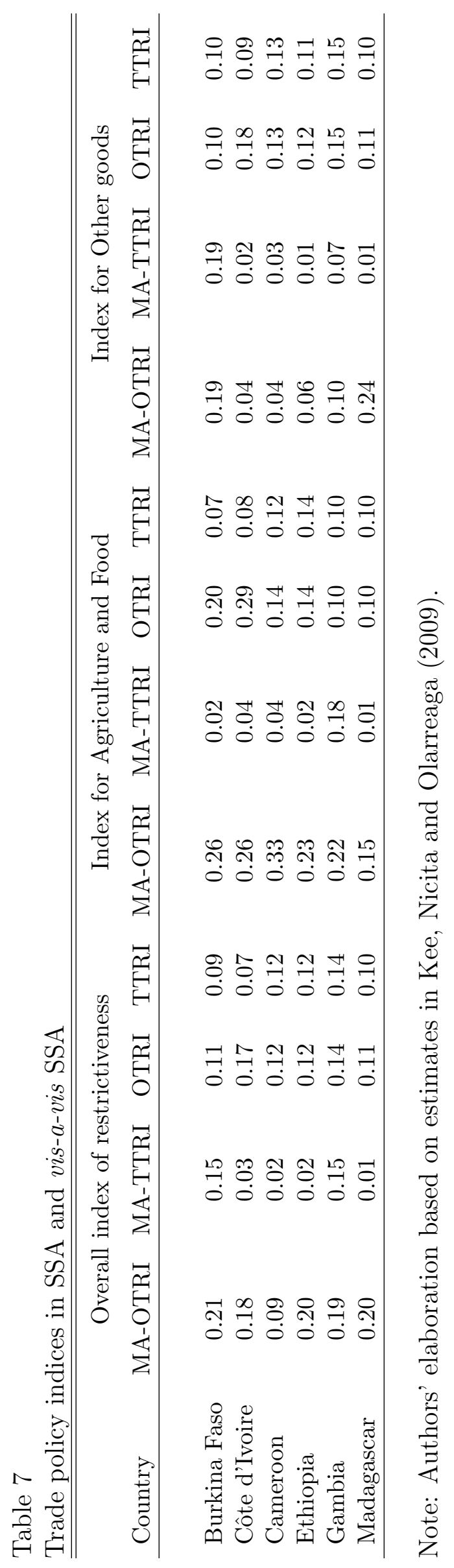




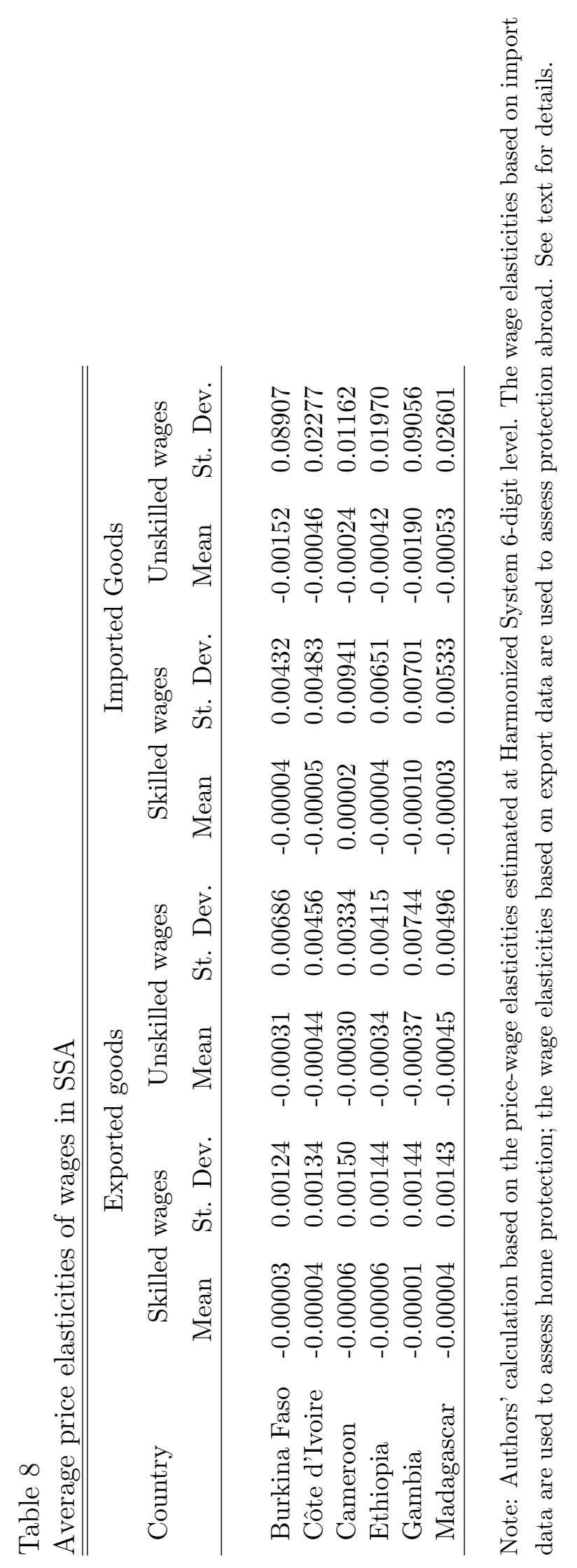




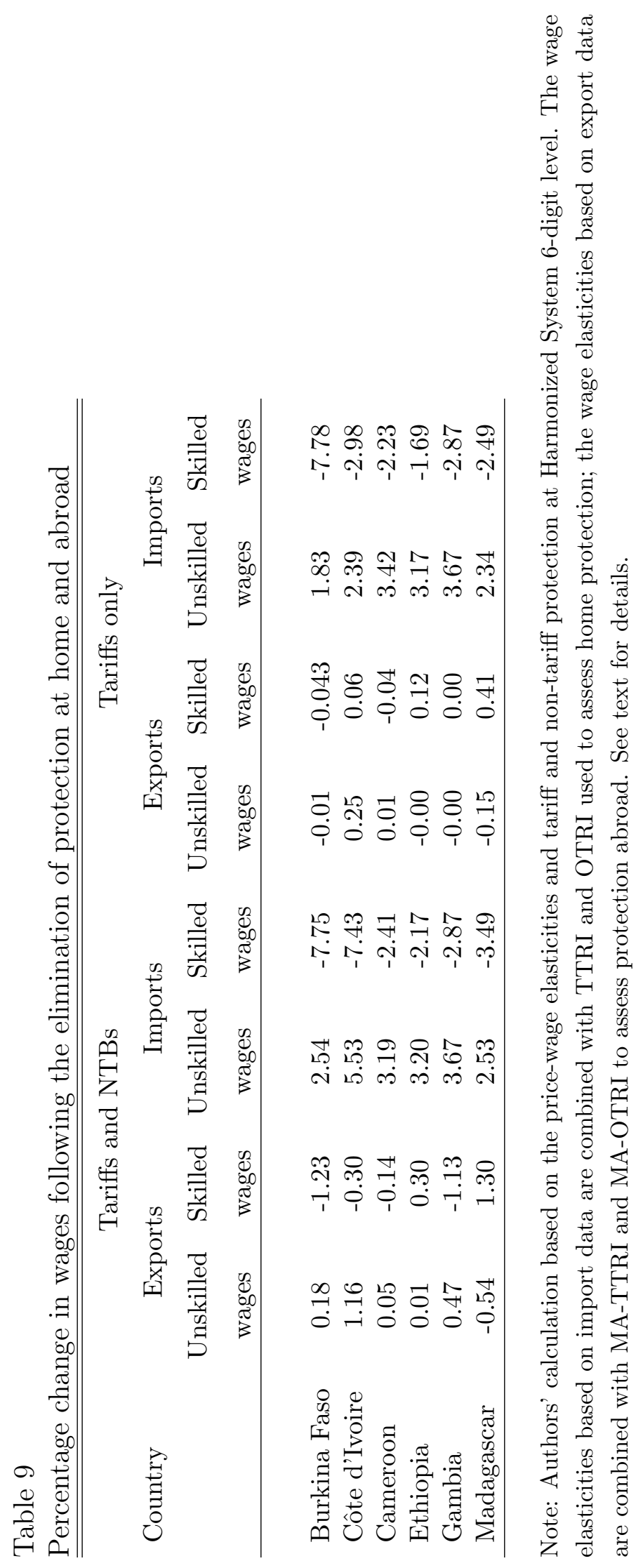


Table 10

Index of pro-poor bias in trade policy (tariffs and non-tariff barriers)

\begin{tabular}{lccccccc}
\hline \hline & \multicolumn{3}{c}{ Own trade policy } & \multicolumn{3}{c}{ Rest-of-the-world trade's policy } \\
Country & Overall & Expenditure & Sales & Wages & Overall & Sales & Wages \\
\hline & & & & & & & \\
Burkina Faso & 0.44 & 0.23 & 0.32 & -0.11 & 0.67 & 0.66 & 0.02 \\
Côte d'Ivoire & 1.53 & -5.04 & 7.21 & -0.64 & -6.80 & -6.81 & 0.01 \\
Cameroon & 1.08 & -0.57 & 2.26 & -0.61 & -0.75 & -0.78 & 0.03 \\
Ethiopia & -0.48 & -0.14 & -0.22 & -0.12 & 0.55 & 0.58 & -0.03 \\
Gambia & 4.72 & 1.50 & 3.46 & -0.24 & -0.01 & -0.07 & 0.06 \\
Madagascar & 0.40 & -0.23 & 0.96 & -0.33 & -1.33 & -1.22 & -0.12 \\
\hline
\end{tabular}

Table 11

Index of pro-poor bias in trade policy (tariffs only)

\begin{tabular}{lccccccc}
\hline \hline & \multicolumn{3}{c}{ Own trade policy } & \multicolumn{3}{c}{ Rest-of-the-world's trade policy } \\
Country & Overall & Expenditure & Sales & Wages & Overall & Sales & Wages \\
\hline & & & & & & & \\
Burkina Faso & -0.09 & -0.23 & 0.24 & -0.10 & 0.04 & 0.04 & 0.00 \\
Côte d'Ivoire & 2.20 & -1.25 & 3.71 & -0.25 & -1.73 & -1.73 & -0.01 \\
Cameroon & 0.58 & -0.64 & 1.81 & -0.59 & -0.22 & -0.23 & 0.01 \\
Ethiopia & -0.43 & -0.14 & -0.22 & -0.08 & 0.06 & 0.07 & -0.01 \\
Gambia & 4.72 & 1.50 & 3.46 & -0.24 & -0.02 & -0.02 & 0.00 \\
Madagascar & 0.48 & -0.23 & 0.96 & -0.25 & -0.07 & -0.03 & -0.04 \\
\hline
\end{tabular}

Table 12

Robustness checks of the index of pro-poor bias in trade policy for top and bottom 20 and 10 of the income distribution

Own trade policy Rest-of-the-world's trade policy

\begin{tabular}{lcccccc} 
Country & $d=40$ & $d=20$ & $d=10$ & $d=40$ & $d=20$ & $d=10$ \\
\hline & & & & & & \\
Burkina Faso & 0.44 & 0.69 & 0.51 & 0.67 & 0.70 & 0.48 \\
Côte d'Ivoire & 1.53 & 0.91 & -0.47 & -6.80 & -9.02 & -9.83 \\
Cameroon & 1.08 & 0.96 & 1.48 & -0.75 & -0.99 & -1.03 \\
Ethiopia & -0.48 & -0.66 & -0.96 & 0.55 & 0.60 & 0.25 \\
Gambia & 4.72 & 6.40 & 6.61 & -0.01 & 0.05 & 0.15 \\
Madagascar & 0.40 & 1.05 & 1.30 & -1.33 & -2.77 & -4.08 \\
\hline
\end{tabular}




\section{Figure 1}

Changes in SSA's household welfare following the removal of own and ROW's trade barriers
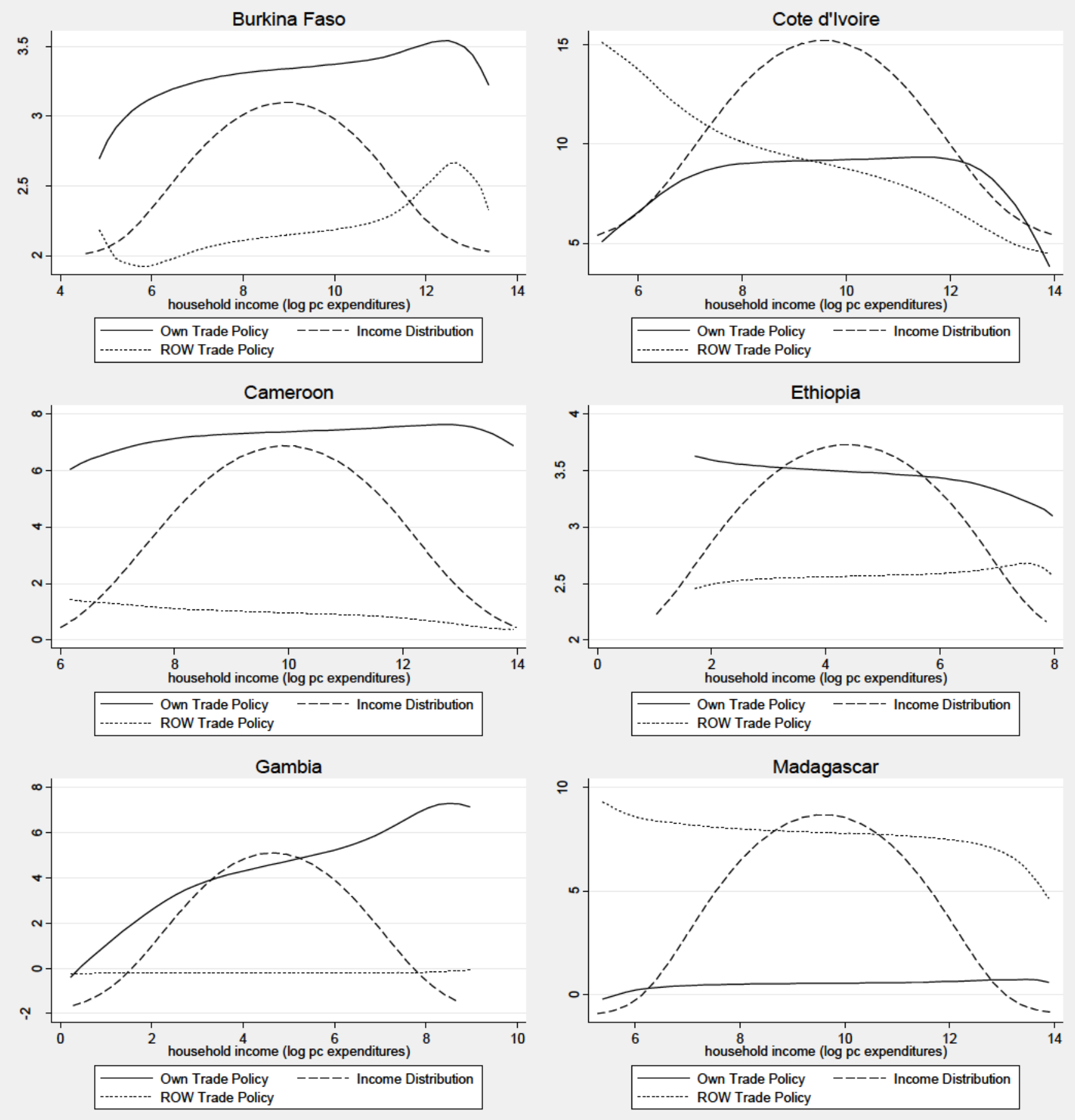